\title{
Mobile Device Application to locate an Interest Point using Google Maps
}

\author{
Leo Willyanto Santoso \\ Informatics Department \\ Petra Christian University \\ Surabaya, Indonesia
}

\author{
Alvin Wilistio \\ Informatics Department \\ Petra Christian University \\ Surabaya, Indonesia
}

\author{
Lily Puspa Dewi \\ Informatics Department \\ Petra Christian University \\ Surabaya, Indonesia
}

\begin{abstract}
Location-based service is a service mechanism that generates geographical location information. This service will certainly give much benefit as there are many people who would like to find public facilities quickly and easily. The needs to know the existence of public facilities quickly and easily is of great demands in the society. Based on the above problems, it is necessary to develop an application that can get any access to the geographical location in mobile phones. Information from this application is expected to help searching for such public facilities. This Searching for interest point information was read using the Location API in Xcode IOS 4.2. The resulting information was displayed on the application of the iPhone. From the test results, the information of the position was influenced by the availability of the information service provider, carrier signal strength, and mobile phone capabilities.
\end{abstract}

Keywords: location based service, Xcode iOS 4.2, Google Maps, public service, interest point

\section{INTRODUCTION}

Information on the location of public facilities at an area is very much needed, especially for a person who is in that area for the first time. Traditionally, a person searches for the information on direction or a specific location is by asking people in the vicinity. The increasing development of technology in the field of telecommunication has driven people to keep abreast with the current development. Many advanced companies in the field of mobile multimedia are competing in introducing new products to meet the needs of the consumers. One of that mobile multimedia is called Navigation Global Positioning System (GPS) or digital map which acts as a sophisticated device on signal receiving and positioning determinant. That product has started to be developed by a multimedia production company due to some frequent phenomena in the society. Some riders or pedestrians often do not know their position when they are in an unrecognized area. They often get lost and do not know the direction to go home. This situation makes them confused, worried and panic. This digital map or GPS navigation device will help a rider or pedestrian not to be afraid of getting lost on the way. In general, the location searching technique usually makes use of two kinds of techniques.

The first technique is by connecting the telecommunication device with the satellite. The second technique is by connecting the telecommunication device with the database server containing the geographical situation of a location which is usually called Geographical Information System (GIS). The first searching method is using the satellite connection or what is usually called Global Positioning System (GPS) [1]. This technique is using a device which can do asynchronization with the satellite to determine the positioning of a location. This application is usually used to find a location based on the coordinate or the latitude and longitude position using satellite as the mediator. The second searching method is using an application used in a browser using computers or mobile phones connected to SIG database server, for instance the foursquare and Google maps. Currently, the positioning technology has already been of much used in the mobile phones. It is even a compulsory capability in a smart phone. Therefore, the use of location searching technology is growing in line with the rapid growth of today software and hardware technology supported by various smart phone vendors. Based on the needs of today society who needs fast and accountable information, a mobile device application to search interest point using Google maps is very much needed $[2,3]$. A visit to a gas station to refuel the vehicle is a routine work in the society. The location of ATM is also needed to withdraw some money fast and easy. Hotels, supermarkets and hospitals are also of much needed on certain conditions. This application is expected to help the users not to bother asking people if they want to go somewhere. The goal of this research is to develop an application for iPhone that can help users determining the closest location to the gas stations, hotels, hospitals, supermarkets and ATMs.

\section{LOCATION BASED SERVICE (LBS)}

Location-based service (LBS) is a service to determine the location of the user and provide certain information needed [4]. LBS can be classified into 3 types. They are Local Information, Traffic and Tracking Information and General Services. Local Information enables users to search services in the vicinity. Traffic and tracking information focuses at assets or people locating. Meanwhile, General Services do not provide information to users. They use the data of the user location. The example of General Services, among others, is emergency services. Various kinds of services have been provided by the use of LBS, such as [5]:

Providing public facility information services, such as hospitals, gas stations, ATM, Hotels etc.

Determining and finding the location of someone or something.

Showing the closest route to go somewhere.

Direction to go to a certain address.

Traffic information system services.

The most important thing in LBS is the method in locating users. In general there are two methods used, using Global Positioning System (GPS) or using Cellular Based stations. The technology using Cellular-Based Station is usually called Cell id.

This technology is usually used at certain locations within limited range as it depends on the BTS (Base Transceiver 
Station) to receive and transmit signals. Therefore GPS technology is currently used due to its high accuracy and its ability to reach the entire surface of the earth. As this navigation device depends entirely on the satellite, the satellite signal is of utmost important. This satellite-based navigation device can not work with a maximum capacity when there are disturbances at the satellite signal.

\section{DESIGN OF THE SYSTEM}

The software developed, in general consists of two parts, the application system to be installed at the mobile phone, and the querying system installed at the Google server in taking and generating data into the application. The main function of the application installed at the mobile phone is to identify the geographical coordinate point of the mobile phone to be sent to the server. Whereas the main function of the querying system installed at the server is to display the geographical coordinate data in the form of information to the application. Fig 1. shows the system design in general. The user can access the location information displayed at the application.

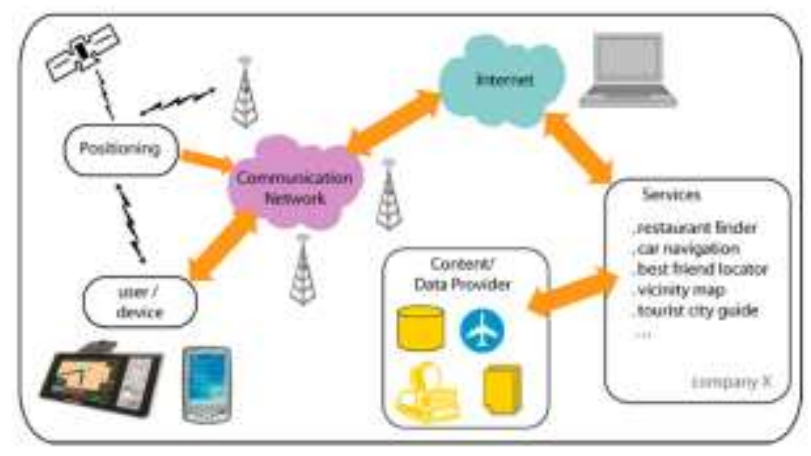

Figure 1. General System Design

\subsection{The design of the software system installed at the Mobile phone}

Fig. 2 shows the flowchart diagram at the software system of the mobile phone. As the mobile phone application is being run, the main menu using the application icon will be displayed first. Centering the application page, the application will make a checking procedure at the device whether the location service has been activated or not. If it has been activated, the application will be ready to receive the input of the location that is going to be located, such as ATM, Hotels, and hospitals.

If the location service has not been activated yet, the application will display the information that the location service has to be activated first. The use of the location service is to locate the initial position of the user to be converted at the form of a coordinate at the system.

At the main form, the user can set the data device_id which is functioning as the mobile phone identifier towards the data at the database server. The user can also set time interval to update the geographical location and arrange the application to be activated or to be deactivated. If the location reader is activated, then the application can run the location reader at the mobile phone. The process that occurs is when the mobile phone application has managed to read the coordinate of the mobile phone location, the data of the coordinate will be displayed at the mobile phone and sent to the server.

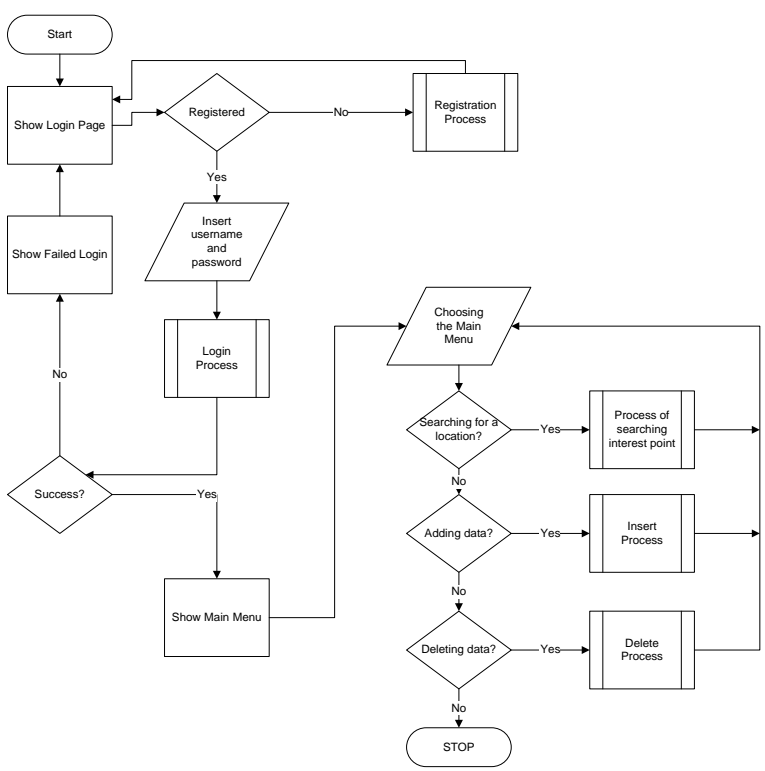

Figure 2. The Flowchart diagram of the software installed at the mobile phone

\subsection{The design of the software installed at the Server}

The software system installed at the server is a form of API from Google Maps. Its main function is to display the geographical location information at the mobile phone using maps, direction from Google Maps. It can add and save the data at the database. It can also delete the location data from the database. The second database is using PHP. This server is used to save the user database which has been logon and registered at the application.

\section{IMPLEMENTATION}

In general the implementation was divided into two: the implementation at the iPhone and at the server. The implementation at the iPhone was using Xcode 4.02 and iOS 4.3. The implementation at the server was using:

Server: Google.com and ta9.petra.ac.id

Apache/2.2.9 (Debian) DAV/2 PHP/5.2.6-1+lenny16 with Suhosin-Patch

MySQL client version: 5.0.51a

PHP extension: My sql.

\section{TESTING}

The first step in running this application was by doing the login as seen at Fig. 3 (a) and registering as a member. Without the registration, the application could not be used. To register, the user could select the register button. If the link succeeded to be touched, then a form of registration would be displayed as seen at Fig. 3 (b)

If the login succeeded to be done correctly, the application would proceed to the main menu that was the search for public service location. There would be a selection to do the search nearby and search by keyword. 


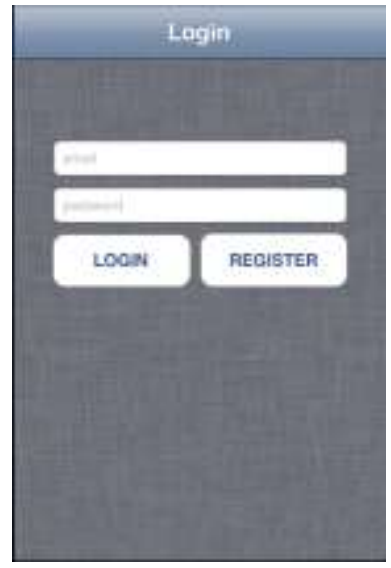

(a)

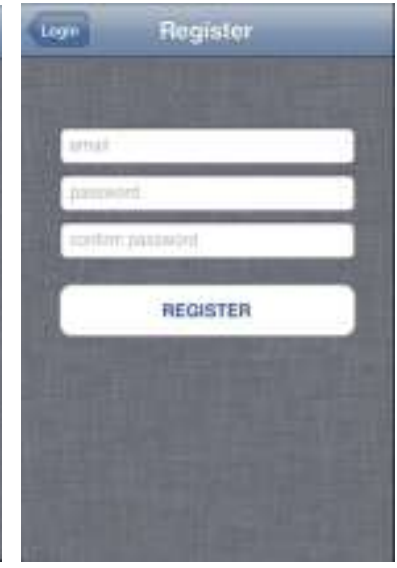

(b)
Figure 3. Application: (a) Login Form, (b) Register Form

\subsection{Steps to search the nearest Public Services Part 1}

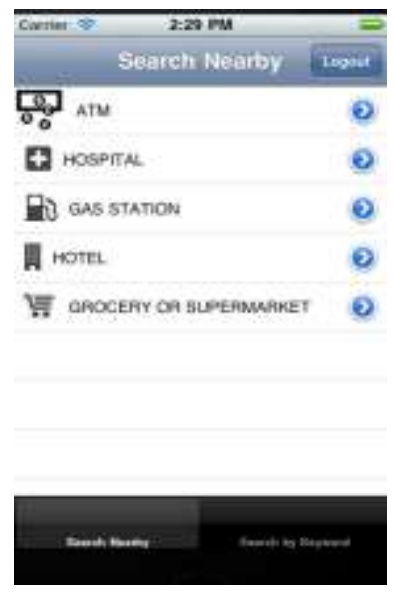

(a)

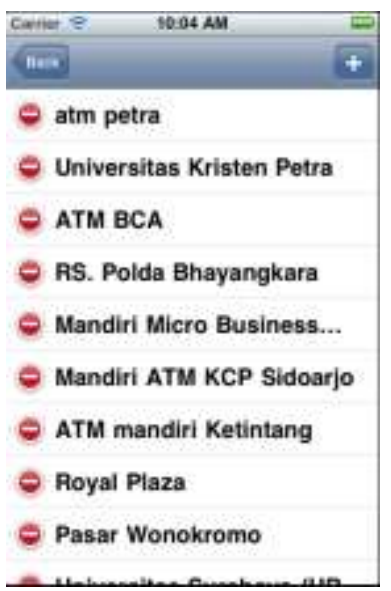

(b)

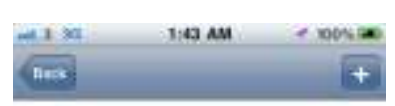

(c)

Figure 4. Application: (a) Main Menu Form, (b) List of nearest public services, (c) Empty

If the user would like to search some location nearby, then the menu search nearby should be touched. Then the application would display the nearest location with the category selected before. If there was no data of the target location at Google, then the application would display an empty table view. It can be seen in Fig. 4.

If there was no data at Google, new data could be added by touching the button with the symbol "+". After entering the names of the location in accordance with the category, the button save should be touched.

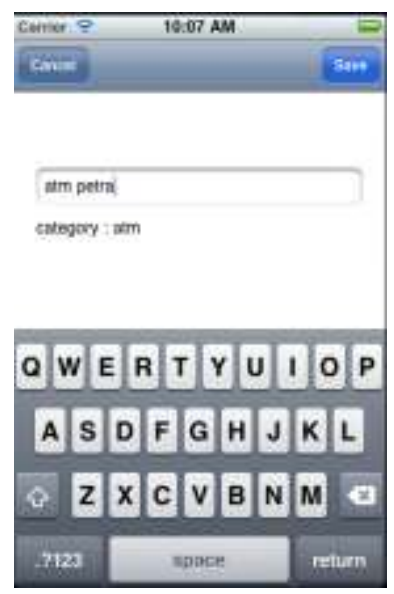

(a)

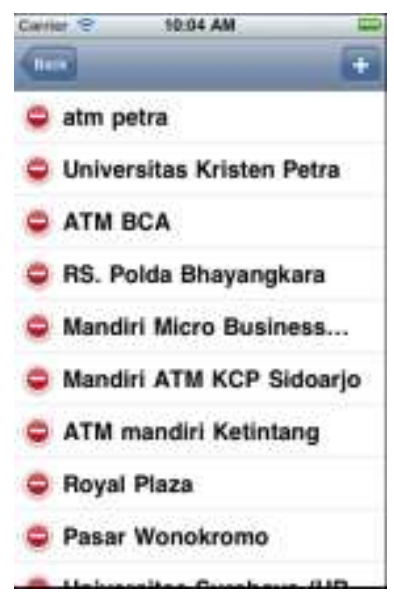

(b)
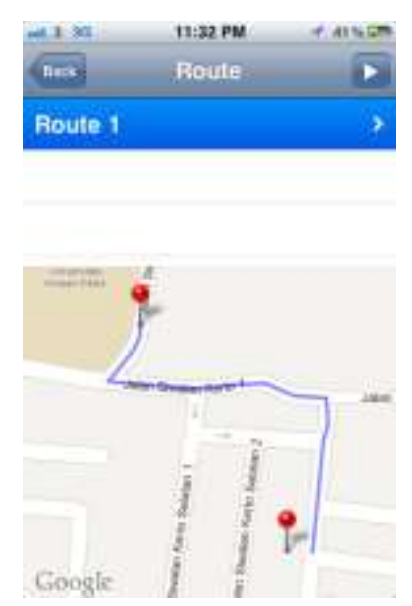

(c)

Figure 5. Application: (a) Adding New Place Form, (b) List of nearest public services after adding process, (c) Routing Form

After the process of adding data was successful, the application could proceed to the list menu as followed. After being added to the Google database, a routing procedure could be made by touching the target location. A map with certain route would be displayed. The application would display the route to the tested location towards the nearest ATM. There was also a narration if the button with the symbol ">" was touched, showing how to reach the target location at the map. It can be seen in Fig. 5.

\subsection{Steps to search the nearest Public Services Part 2}

This testing was using the location at Petra Christian University in searching for a hospital. It can be seen in Fig. 6 . 


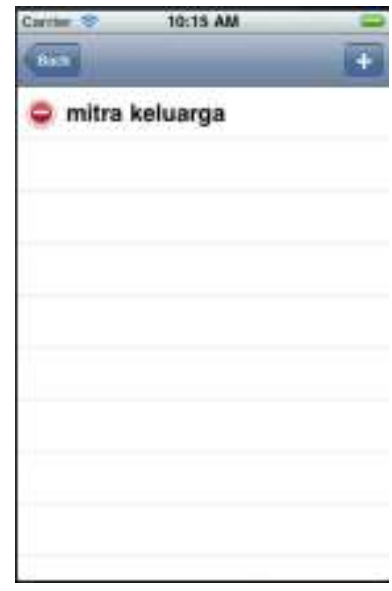

(a)
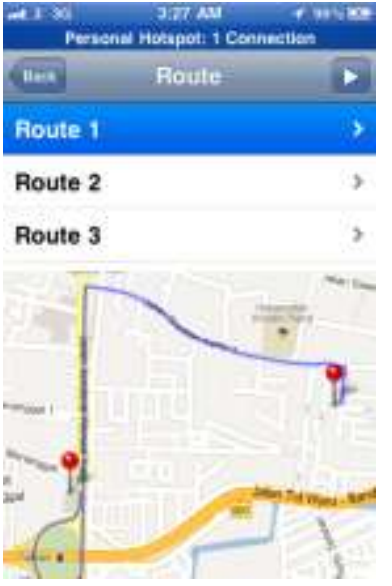

(b)

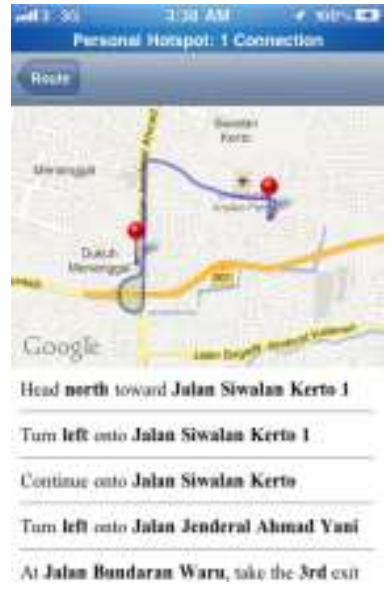

(c)
Figure 6. Application: (a) Result after Searching Process, (b) $1^{\text {st }}$ Alternative Routing Process, (c) Direction

The search for the hospital was similar to that search of ATM. The symbol of Hospital at the category menu was touched. A map showing the route to the location of the hospital would be displayed.

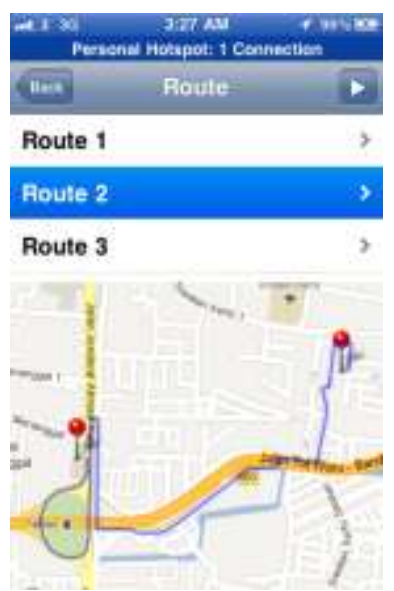

(a)

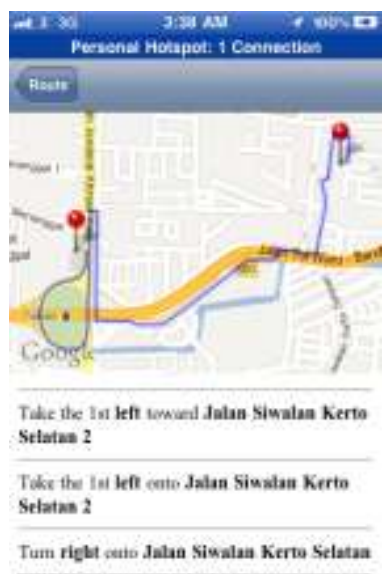

(b)

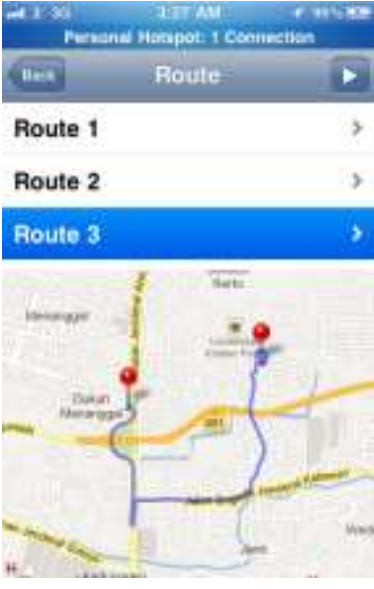

(c)

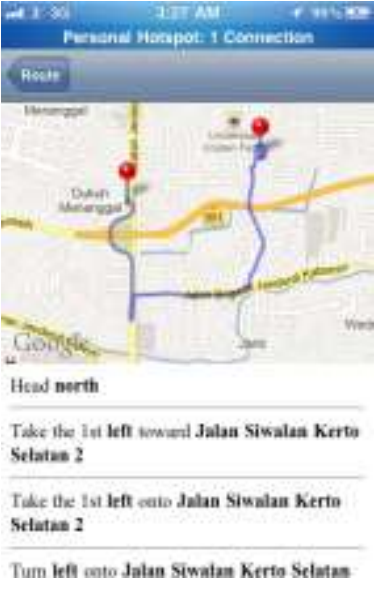

(d)
Figure 7. Application: (a) $2^{\text {nd }}$ Alternative Routing Process, (b) Direction, (c) $3^{\text {rd }}$ Alternative Routing Process, (d) Direction

\subsection{Steps to Add New Locations to the Application}

The following process was the way of adding a new location at the application. The Fig. 8 (a) is the example of inserting a new location at the Supermarket category.

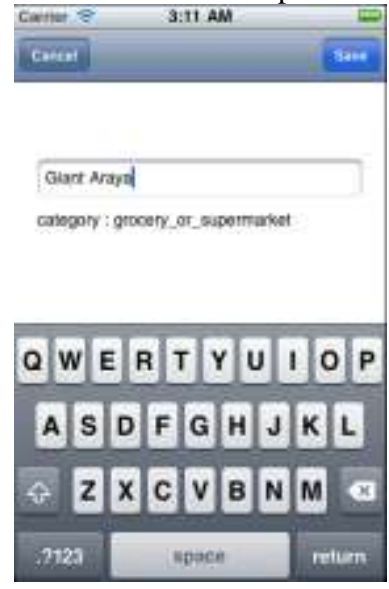

(a)

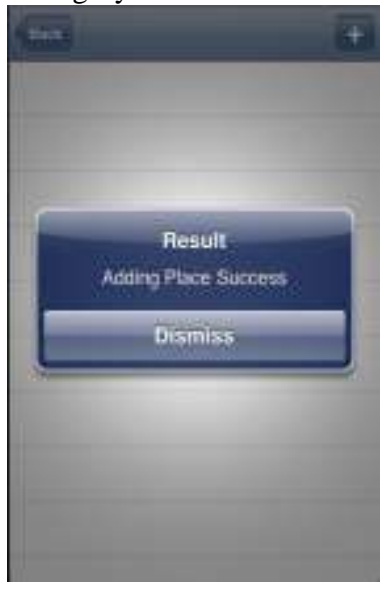

(b)

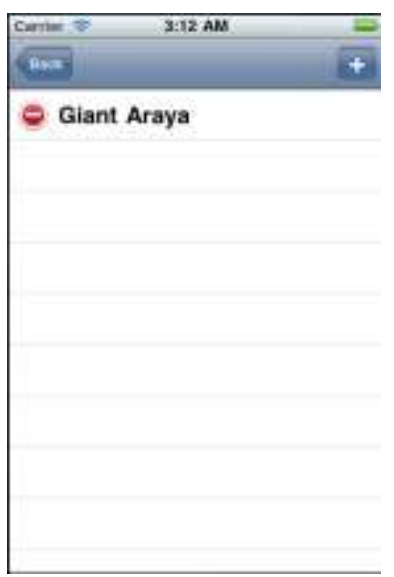

(c)

Figure 8. Application: (a) Adding New Place Form, (b) Confirmation after adding process, (c) List Form 
A form would appear, ready to be inserted the name of a location into the database. After the save button was touched, the name of the location would be saved and added to the database. A pop up result would appear as seen at Fig. 8 (b). The data of the location added would be displayed at the search list as seen at Fig. 8 (c).

\section{CONCLUSION AND SUGGESTION}

\subsection{Conclusion}

Based in the development and testing of the application by detecting the geographical location installed at the mobile phone using API Google Location, it was concluded that:

- The mobile phone application was able to identify the coordinate of the geographical location of the mobile phone at a certain time.

The success of the application to read the coordinate of the geographical location was influenced by the availability of the information service provider, carrier signal strength, GPS signal strength and the availability of the mobile phone capabilities.

The geographical coordinate could be read accurately based on the testing of the geographical coordinate accuracy in Surabaya.

- The application requires a stable signal and data connection to guarantee the success of the process of the transmission of the coordinate data to the server.

- The application could be installed at some mobile phones simultaneously based on the testing.

- The mobile phone application required a lot of battery power source.

- The application can not be free open source software, as Google limits the use of API to a maximum of 25.000 map load. Payment to Google is required if more map load is needed.

- A long approval process allowed the possibility of delays in inputting and managing the location that has been input.

- $\quad$ A long querying process of inputting a new location to the Google server, was allowing the possibility of the application developer to have to create a database first.
It took some time to route Google to do the search for the first time. Therefore the sophisticated database availability is a necessity in routing

\subsection{Suggestion}

The following suggestions are expected to encourage further developments, such as:

- The mobile phone application can be developed at other platforms supporting Google API Location such as Android, Symbian and Windows phone.

- $\quad$ The mobile phone application can be developed further to save the required battery resources.

- $\quad$ It might be necessary to try other API locations such as API Bing, yellow pages etc.

- Before developing this application, a complete database on public services has to be created first. Otherwise it will create problems in running the application.

\section{REFERENCES}

[1] X.Y. Zhaoa, "On processing GPS tracking data of spatiotemporal car movements: a case study", Journal of Location Based Services, Vol. 9, No. 4, 2015, pp. 235253.

[2] Udell, S. 2009. Beginning Google Maps Mashups with Mapplets, KML, and GeoRSS. New York, NY: Apress.

[3] Peterson, M. P. 2012. Online Mapping with APIs, Online Maps with APIs and Mapservices (M. P. Peterson, ed.), Springer, pp. 3-12.

[4] Kremera, D and Schliedera, C., "Less is more: empirical design criteria for a tourist place recommendation service which decelerates the visiting experience", Journal of Location Based Services, Vol. 8, No. 4, 2014, pp. 268284.

[5] S, Hu, 2012. Multimedia Mapping on the Internet Using Commercial APIs, Online Maps with APIs and Mapservices (M. P. Peterson, ed.), Springer, pp. 61-71. 